\title{
EMergência de Bidens pilosa em Diferentes Profundidades De SEMEADURA ${ }^{1}$
}

\author{
Seed Emergence of Bidens pilosa at Different Sowing Depths \\ SOUZA, M.C. ${ }^{2}$, PITELLI, R.A. ${ }^{3}$, SIMI, L.D. ${ }^{4}$ e OLIVEIRA, M.C.J. ${ }^{5}$
}

\begin{abstract}
RESUMO - Bidens pilosa é uma das mais importantes plantas daninhas que ocorrem em lavouras anuais e perenes da região Centro-Sul do Brasil. A grande capacidade de produção de aquênios é uma das suas principais estratégias de sobrevivência, e o conhecimento das condições fundamentais para germinação e emergência das plântulas é essencial para predição do crescimento populacional e para a elaboração de plano de manejo de suas infestações e de seus biótipos resistentes aos herbicidas. Foram conduzidos ensaios em condições de casa de vegetação, onde foi avaliada a emergência de aquênios de $B$. pilosa em diferentes profundidades $(0,1,2,3,4$ e $5 \mathrm{~cm})$. Os experimentos foram conduzidos nos meses de maio, agosto e novembro de 2006 e em março de 2007. Os resultados mostraram que a emergência de plântulas de picão-preto foi bastante afetada pela localização do aquênio no perfil do solo, ocorrendo expressiva redução a partir de $2 \mathrm{~cm}$ de profundidade. Essa característica da biologia reprodutiva do picão-preto é importante para a formação de densos bancos de sementes em solos submetidos ao preparo convencional, onde grande parte da chuva de sementes é nele incorporada.
\end{abstract}

Palavras-chave: picão-preto, germinação, biologia reprodutiva.

ABSTRACT - Bidens pilosa is one of the major weeds in annual and perennial crops in mid-southern Brazil. High seed production is one of its most important survival strategies and the knowledge of the fundamental conditions for seedling germination and emergence is essential to establish prediction models of its population growth and to elaborate management models for control and prevention of herbicide resistant populations. This research aimed to understand the importance of $\boldsymbol{B}$. pilosa seed depth in the soil profile to enhance its germination and seedling emergence potential. Thus, four assays were carried out under greenhouse conditions and the seeds were sown at $0,1,2,3$, 4 , and $5 \mathrm{~cm}$ from the soil surface. The emergence of $\boldsymbol{B}$. pilosa seedlings was reduced as sowing depth was increased, with drastic reduction from two centimeters. This reproductive biology feature presented by $\boldsymbol{B}$. pilosa is very important for the formation of dense seed banks in soils submitted to conventional tillage system.

Keywords: common blackjack, germination, reproductive biology.

\section{INTRODUÇÃO}

Bidens pilosa, vulgarmente conhecida como picão-preto, é uma planta originária da América tropical e disseminada para várias regiões tropicais e subtropicais do mundo, sendo uma das mais importantes plantas daninhas na América do Sul. Essa planta é encontrada em praticamente todo o território brasileiro, com maior concentração nas áreas agrícolas da região Centro-Sul (Kissmann \& Groth, 1999). Suas plantas têm profusa e longa

Recebido para publicação em 17.1.2008 e na forma revisada em 18.2.2009.

2 Biólogo, FCAV/UNESP, <marcelo_claro@yahoo.com.br>; ${ }^{3}$ Professor Titular do Dep. de Fitossanidade - FCAV/UNESP, Via de Acesso Prof. Paulo Donato Castellane, s/n, 14884-900 Jaboticabal-SP, <rapitelli@ecosafe.agr.br>; ${ }^{4}$ Biólogo, FCAV/UNESP, $<$ lucasdsimi@yahoo.com.br>; ${ }^{5}$ Graduando em Agronomia,FCAV/UNESP, <melina_cais@yahoo.com.br>. 
produção de aquênios como uma das principais características de agressividade da espécie, o que é um dos atributos que garantem sua sobrevivência em agroecossistemas. Segundo os autores supracitados, apenas uma planta pode produzir 3.000 sementes no ciclo e, após a maturação, poucas delas têm germinação imediata. A grande maioria das sementes apresenta dormência, o que proporciona condições para a formação e sobrevivência de fartos bancos de sementes em áreas agrícolas e garante a sobrevivência da planta em períodos adversos (Voll et al., 1997).

O banco de sementes e propágulos vegetativos no solo constitui a principal fonte de regeneração de plantas daninhas em áreas agrícolas (Carmona, 1992), não devendo ser considerado um simples estoque de diásporos, pois apresenta dinâmica própria, a qual varia com a espécie, as condições da semente, a ocorrência de predadores e os fatores ambientais (Carmona \& Murdoch, 1995). O banco de sementes de um solo pode ser considerado como a reserva de sementes e propágulos vegetativos tanto em profundidade quanto em sua superficie, constituindo a origem do ciclo de vida das espécies vegetais (Roberts, 1981; Fernández-Quintanilla et al., 1991). Também constitui um arquivo de informações das condições ambientais e práticas culturais anteriores, sendo fator importante de avaliação do potencial de infestação das plantas daninhas no presente e no futuro (Templeton \& Levin, 1979).

A distribuição vertical de sementes ao longo do perfil do solo, que apresenta estreita correlação com o tipo de preparo do solo, é importante no condicionamento das condições ambientais às quais as sementes estão sujeitas. O conhecimento da dinâmica da germinação e da emergência de propágulos de plantas daninhas em diferentes profundidades do solo é fundamental para a proposição de métodos mais racionais de manejo de plantas daninhas (Murdoch \& Carmona, 1993).

$\mathrm{Na}$ determinação de modelos de crescimento de populações vegetais, são vários os parâmetros de entrada de informações fundamentais, desde as características de germinação e emergência das plântulas, passando pelos fatores que afetam o crescimento e a sobrevivência das plantas até as ocorrências de fatores que afetam a dispersão dos diásporos (Radosevich et al., 2007). Dos fatores que determinam a passagem dos estádios fenológicos de semente para plântulas, a profundidade do diásporo no perfil do solo é um dos mais importantes e, sem dúvida, sua avaliação é essencial para o desenvolvimento de modelos de crescimento populacional da espécie e, com fins práticos, para avaliar a eficácia de métodos mecânicos, químicos, isolados ou associados, no controle das plantas daninhas (Brighenti et al., 2003; Canossa et al., 2007). Dessa forma, estudos sobre a dinâmica populacional de diásporos (Radosevich et al., 2007) subsidiam estratégias de manejo (Brihenti et al., 2003) e auxiliam no entendimento da dinâmica de formação do banco de sementes em solos agrícolas.

O presente trabalho teve por objetivo avaliar a capacidade de emergência de aquênios de $B$. pilosa localizados em diferentes profundidades no perfil de um substrato formado por terra coletada na camada arável de Latossolo Vermelho distrófico, textura arenosa, em condições de casa de vegetação.

\section{MATERIAL E MÉTODOS}

Quatro experimentos foram conduzidos em condições de casa de vegetação no Núcleo de Estudo e Pesquisa Ambientais em Matologia (NEPEAM), na Faculdade de Ciências Agrárias e Veterinárias - UNESP, Jaboticabal-SP.

Para os estudos, foram utilizados vasos plásticos com capacidade de $3 \mathrm{~L}$, pintados externamente com tinta cor alumínio, para evitar que a luminosidade pudesse interferir nos resultados. A terra utilizada foi coletada da camada arável de um Latossolo Vermelho distrófico (Embrapa, 2006), com granulometria de $380 \mathrm{~g} \mathrm{~kg}^{-1}$ de argila, $50 \mathrm{~g} \mathrm{~kg}^{-1}$ de silte e $570 \mathrm{~g} \mathrm{~kg}^{-1} \mathrm{de}$ areia (Departamento de Solos da UNESP Jaboticabal.). A terra foi seca à sombra e, em seguida, passada em uma peneira de malha de $5 \mathrm{~mm}$ antes de ser locada nos vasos.

As sementes utilizadas foram coletadas a partir de plantas-estoque cultivadas em casas de vegetação e que apresentavam bom estado sanitário e nutricional nos meses de abril, julho e outubro de 2006 e fevereiro de 2007. As coletas ocorreram com antecedência máxima de 15 dias da instalação de cada experimento, 
visando evitar que as sementes entrassem em processo de dormência.

O delineamento experimental adotado foi inteiramente casualizado, com seis tratamentos e cinco repetições. Os tratamentos constaram das seguintes profundidades de semeadura: $0,1,2,3,4$ e $5 \mathrm{~cm}$. Cada vaso foi considerado uma unidade experimental e foram colocadas 50 sementes por vaso.

Na condução do ensaio, a umidade do solo foi mantida em $50 \%$ da capacidade de embebição, determinada pelo método gravimétrico. As sementes foram consideradas germinadas quando a protrusão dos folíolos se tornou visivel sobre o solo, de acordo com o método (adaptado) utilizado por Machado Neto \& Pitelli (1988) em experimento conduzido para emergência de amendoim-bravo. No caso dos aquênios localizados na superficie do solo, a emergência foi considerada quando as plântulas apresentavam início de abertura dos cotilédones. Diariamente, as plântulas emergidas foram cortadas próximo ao solo e contadas, até o final do período de germinação.

Com os dados diários de emergência, calculou-se o índice de velocidade de emergência (IVE) para cada profundidade de semeadura, segundo a fórmula proposta por Maguire (1962), e o percentual de germinação para cada estação do ano. As médias dos tratamentos foram comparadas por meio do teste de Tukey a $5 \%$ de probabilidade.

\section{RESULTADOS E DISCUSSÃO}

Os dados referentes à emergência dos aquênios locados na superfície $(0 \mathrm{~cm})$ não foram considerados devido à elevada incidência de fungos, que afetou o desenvolvimento do processo germinativo e de expansão da plântula. No entanto, essa informação é importante e deve ser investigada com metodologia própria.

$\mathrm{Na}$ Figura 2 estão representadas as médias cumulativas das emergências de plântulas de picão-preto nos quatro experimentos. No ensaio realizado em maio de 2006, observou-se que sementes de Bidens pilosa colocadas entre 1 e $3 \mathrm{~cm}$ de profundidade emergiram a partir dos sete dias após semeadura (DAS); sementes colocadas a $4 \mathrm{~cm}$ de profundidade emergiram a partir de 10 DAS; e não ocorreu emergência para as sementes colocadas a $5 \mathrm{~cm}$ de profundidade. No ensaio realizado em agosto de 2006, as sementes colocadas a $1 \mathrm{~cm}$ de profundidade emergiram a partir dos 7 DAS; sementes colocadas a 2 e $3 \mathrm{~cm}$ emergiram ao redor dos 16 DAS; e não ocorreu emergência para sementes colocadas a 4 e $5 \mathrm{~cm}$ de profundidade. No ensaio realizado em novembro de 2006, as sementes colocadas a 1, 2, 3, 4 e $5 \mathrm{~cm}$ iniciaram sua emergência entre 2 e 4 DAS. Para o ensaio realizado em março de 2007, as sementes colocadas a 1, 2, 3 e $4 \mathrm{~cm}$ iniciaram sua emergência ao redor dos 8 DAS; e as sementes colocadas a $5 \mathrm{~cm}$ de profundidade emergiram a partir dos 18 DAS.

Na Tabela 2, observa-se interação significativa na emergência de $B$. pilosa em relação à profundidade de semeadura. A maior porcentagem de emergência de plântulas de Bidens pilosa ocorreu a partir de aquênios locados a $1 \mathrm{~cm}$ e a menor foi observada em sementes ao redor de $5 \mathrm{~cm}$ de profundidade. Esses dados estão de acordo com os de alguns autores. Lorenzi (2000) comenta que a emergência de plântulas de picão-preto é decorrente de aquênios localizados até $1 \mathrm{~cm}$ de profundidade. Sahoo \& Jhá (1998) observaram redução de $66 \%$ na emergência de plântulas de picão-preto quando as sementes foram semeadas a apenas $2 \mathrm{~cm}$ de profundidade.

A variação da capacidade germinativa do picão-preto nos experimentos conduzidos nas diferentes épocas do ano é um ponto importante no manejo dessa planta. Esse comportamento pode ser intrínseco da semente e estar relacionado às condições fisiológicas da planta por ocasião da frutificação ou aos efeitos das variáveis climáticas durante o processo de germinação e emergência das plântulas no período de cada experimento.

Na Figura 1 estão apresentados os valores da temperatura do ar durante os períodos experimentais. No período experimental de maio de 2006 foi observada a menor temperatura média $\left(18,8^{\circ} \mathrm{C}\right)$, com valores variando entre $16,2{ }^{\circ} \mathrm{C}$ e $21,5^{\circ} \mathrm{C}$. A temperatura média no período experimental de agosto de 2006 foi de $22,4^{\circ} \mathrm{C}$, com valores variando entre $16,7^{\circ} \mathrm{C}$ e $25,8^{\circ} \mathrm{C}$. Esses foram os experimentos com baixas taxas de emergência. Em maio, os mais baixos valores de temperatura 
ocorreram no início do período, ao passo que em agosto ocorreu o contrário. Independentemente do período em que as baixas temperaturas ocorreram, houve uma quantidade final de plântulas emergidas bastante similar nos experimentos de maio e agosto.

Nos experimentos conduzidos em novembro de 2006 e março de 2007, as temperaturas médias e os valores extremos foram mais elevados. Em novembro, a temperatura média foi de $25,1^{\circ} \mathrm{C}$, variando entre $23,1^{\circ} \mathrm{C}$ e $28,5^{\circ} \mathrm{C}$. Para o período experimental de março de 2007, a temperatura média foi de $24,5^{\circ} \mathrm{C}$, com valores variando entre $21,2{ }^{\circ} \mathrm{C}$ e $26,2^{\circ} \mathrm{C}$. Nesses dois períodos ocorreram as mais elevadas taxas de emergência das plântulas de picão-preto. É possivel que a temperatura tenha sido um dos fatores ecológicos que contribuíram para a variação observada nos quatro experimentos, pois as duas menores taxas de emergência foram observadas nos períodos com menores temperaturas.

Na Tabela 1 estão apresentados os valores calculados para o índice de velocidade de emergência (IVE) de Bidens pilosa nas diferentes épocas e profundidades do aquênio no solo. Para os experimentos conduzidos nos meses de maio e novembro de 2006, observouse maior emergência a $1 \mathrm{~cm}$ de profundidade. No experimento conduzido em agosto de 2006 não ocorreu variação significativa no IVE e, em março de 2007, ocorreu redução significativa nas maiores profundidades. Os valores

Tabela 1 - Valores dos índices de velocidade de emergência de aquênios de Bidens pilosa locados em diferentes profundidades do solo

\begin{tabular}{|c|c|c|c|c|}
\hline \multirow{2}{*}{$\begin{array}{c}\text { Profundidade } \\
(\mathrm{cm})\end{array}$} & \multicolumn{4}{|c|}{ IVE } \\
\cline { 2 - 5 } & maio/06 & ago/06 & nov/06 & mar/07 \\
\hline 1 & $0,44 \mathrm{~A}$ & $0,35 \mathrm{~A}$ & $5,15 \mathrm{~A}$ & $0,90 \mathrm{~A}$ \\
\hline 2 & $0,18 \mathrm{~B}$ & $0,07 \mathrm{~A}$ & $1,78 \mathrm{~B}$ & $0,89 \mathrm{~A}$ \\
\hline 3 & $0,09 \mathrm{~B}$ & $0,14 \mathrm{~A}$ & $1,21 \mathrm{~B}$ & $0,90 \mathrm{~A}$ \\
\hline 4 & $0,04 \mathrm{~B}$ & $0,00 \mathrm{~A}$ & $0,84 \mathrm{~B}$ & $0,25 \mathrm{AB}$ \\
\hline 5 & $0,00 \mathrm{~B}$ & $0,00 \mathrm{~A}$ & $0,79 \mathrm{~B}$ & $0,02 \mathrm{~B}$ \\
\hline DMS & 0,20 & 0,41 & 1,76 & 0,76 \\
\hline $\mathrm{CV}$ & 69,72 & 255,16 & 47,61 & 68,09 \\
\hline $\mathrm{F}$ & $14,29^{* *}$ & $2,33^{\mathrm{NS}}$ & $19,36^{* *}$ & $5,49 * *$ \\
\hline
\end{tabular}

$* *$ significativo a $5 \%$ de probabilidade pelo teste $\mathrm{F}$.

Médias seguidas de letras iguais nas colunas não diferem significativamente pelo teste de Tukey a $5 \%$ de probabilidade.

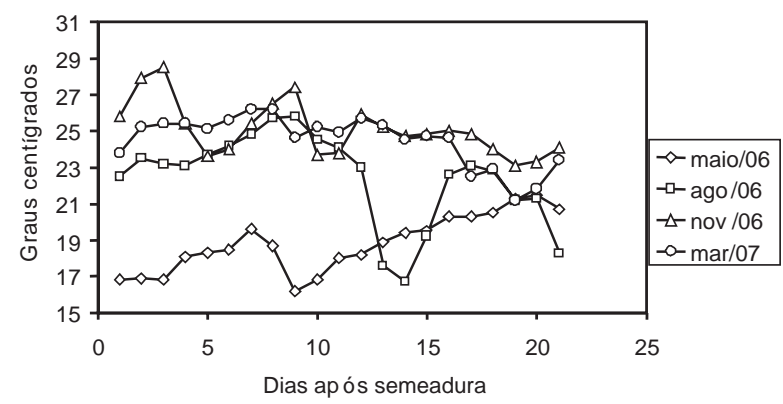

Figura 1 - Variação de temperatura média diária do ar no período de condução dos experimentos em casa de vegetação.

do IVE estão próximos aos encontrados por Muniz Filho et al. (2004) em avaliações realizadas em campo sobre emergência de picão-preto, ocorrendo significativa redução de IVE conforme aumenta a profundidade de semeadura. Esses resultados estão em consonância com os obtidos por Tolledo et al. (1993), que, em estudos com Xanthium strumarium, também observaram maiores indices de velocidade de emergência em menores profundidades do solo, com quase $70 \%$ de emergência, porém foram baixos nos quatro experimentos, quando comparados com resultados obtidos por Canossa et al. (2007) em experimentos com Alternanthera tenella, em que foram atingidos valores de IVE pouco acima de 20 em sementes locadas na superficie do solo. No entanto, o baixo índice de velocidade de emergência pode constituir também parte da estratégia de sobrevivência do picão-preto para formação de densos bancos de sementes.

Tabela 2 - Percentual de emergência de plântulas de Bidens pilosa, com valores transformados em $\operatorname{arcsen} \sqrt{x+0,5}$

\begin{tabular}{|c|c|c|c|c|}
\hline \multirow{2}{*}{$\begin{array}{c}\text { Profundidade } \\
(\mathrm{cm})\end{array}$} & \multicolumn{4}{|c|}{ Porcentagem de emergência } \\
\cline { 2 - 5 } & maio/06 & ago/06 & nov/06 & mar/07 \\
\hline 1 & $13,57 \mathrm{~A}$ & $12,63 \mathrm{~A}$ & $52,94 \mathrm{~A}$ & $29,21 \mathrm{~A}$ \\
\hline 2 & $9,35 \mathrm{AB}$ & $8,34 \mathrm{AB}$ & $27,90 \mathrm{~B}$ & $30,71 \mathrm{~A}$ \\
\hline 3 & $7,71 \mathrm{~B}$ & $5,06 \mathrm{~B}$ & $17,37 \mathrm{~B}$ & $24,18 \mathrm{AB}$ \\
\hline 4 & $6,07 \mathrm{~B}$ & $4,05 \mathrm{~B}$ & $16,84 \mathrm{~B}$ & $15,34 \mathrm{BC}$ \\
\hline 5 & $4,05 \mathrm{~B}$ & $4,05 \mathrm{~B}$ & $14,83 \mathrm{~B}$ & $6,07 \mathrm{C}$ \\
\hline $\mathrm{DMS}$ & 5,40 & 5,68 & 13,48 & 12,02 \\
\hline $\mathrm{CV}$ & 34,99 & 43,94 & 27,44 & 30,11 \\
\hline $\mathrm{F}$ & $8,00 * *$ & $7,56 * *$ & $24,90 * *$ & $13,21 * *$ \\
\hline
\end{tabular}

**significativo a $5 \%$ de probabilidade pelo teste $\mathrm{F}$.

Médias seguidas de letras iguais nas colunas não diferem significativamente pelo teste de Tukey a $5 \%$ de probabilidade. 

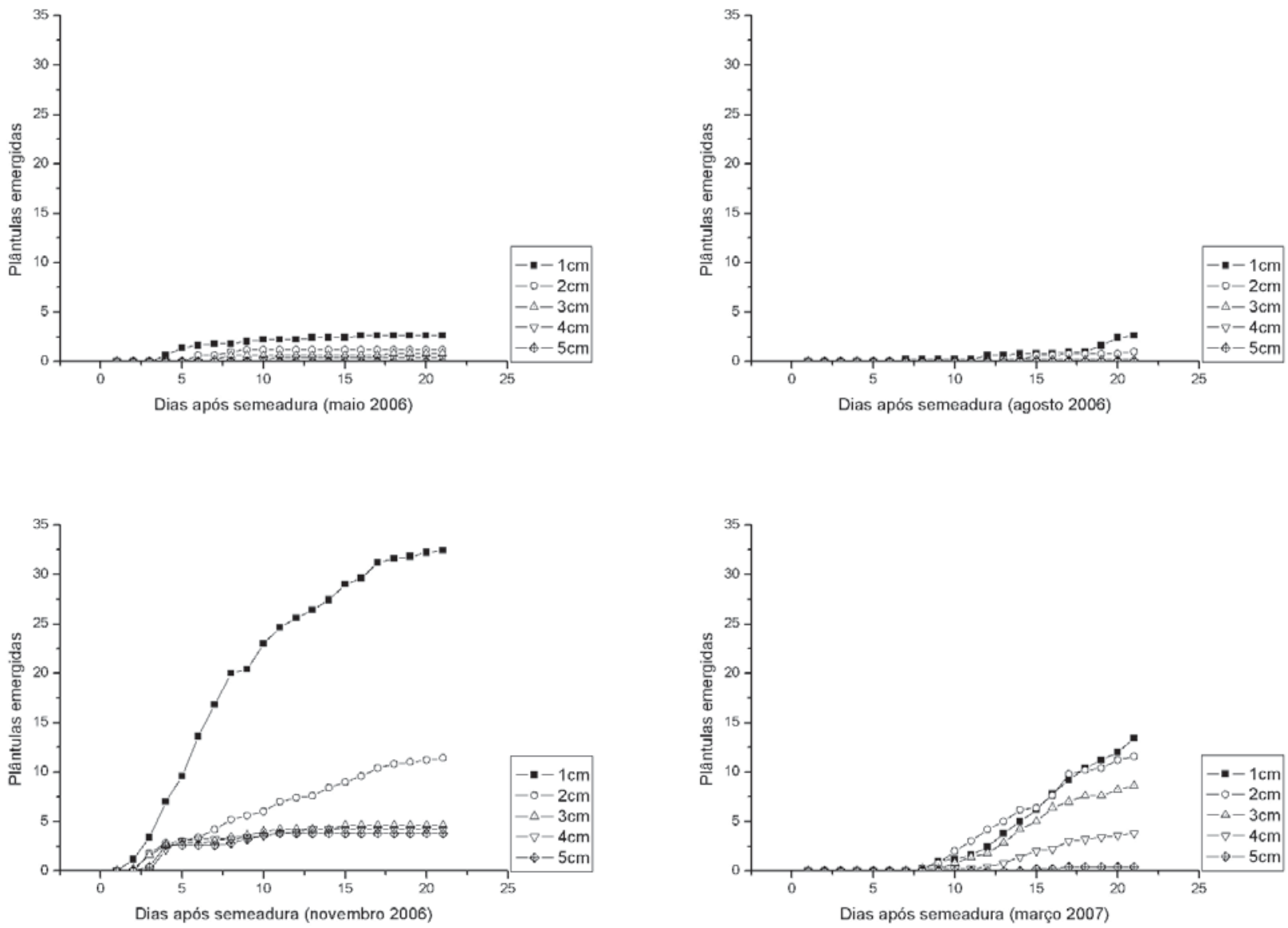

Figura 2 - Marcha cumulativa do percentual de emergência de plântulas de Bidens pilosa provenientes de aquênios locados em diferentes profundidades no substrato.

Os resultados mostraram que emergência de plântulas do picão-preto foi bastante afetada pela localização do aquênio no perfil do solo, ocorrendo expressiva redução da emergência em todas as profundidades em relação a $1 \mathrm{~cm}$ de semeadura. Essa característica da biologia reprodutiva do picão-preto é importante para a formação de densos bancos de sementes em solos submetidos ao preparo convencional, onde grande parte da chuva de sementes é nele incorporada. Os resultados também podem ser úteis para explicar as grandes densidades dessa planta daninha em áreas sob plantio direto, onde as sementes são depositadas na superficie do solo.

Em relação ao percentual germinativo (Tabela 2), observou-se maior percentual nas menores profundidades e redução no percentual germinativo a partir de $3 \mathrm{~cm}$ de profundidade.
Esse comportamento pode ser decorrente do efeito isolado ou da combinação de vários fatores fundamentais para o processo germinativo, como exposição à luz (Klein \& Felipe, 1991), necessidade de uma determinada amplitude de variação térmica (Bewley \& Black, 1986) e disponibilidade de oxigênio (Bewley \& Black, 1986), ou para o processo de emergência, como a quantidade de reservas para suportar o crescimento pela camada do solo.

\section{LITERATURA CITADA}

BEWLEY, J. D.; BLACK, M. Seeds. Physiology of development and germination. New York: Plenum PressPublishing Corporation, 1986. p. 37.

BRIGHENTI, A. M.; VOLL, E.; GAZZIERO, D. L. P. Biologia e manejo do Cardiospermum halicacabum. Planta Daninha, v. 21, n. 2, p. 229-237, 2003 
CANOSSA, R. S. et al. Profundidade de semeadura afetando a emergência de plântulas de Alternanthera tenella. Planta Daninha, v. 25, n. 4, p. 719-725, 2007.

CARMONA, R. Problemática e manejo de bancos de sementes de invasoras em solos agrícolas. Planta Daninha, v. 10, n. $1 / 2$, p. $5-16,1992$

CARMONA, R.; MURDOCH, A. J. Interactions of temperature and dormancy-relieving compounds on the germination of weed seeds. Seed Sci. Res., v. 5, n. 4, p. 227-236, 1995.

EMPRESA BRASILEIRA DE PESQUISAAGROPECUÁRIA - EMBRAPA. Centro Nacional de Pesquisa Agropecuária de Solos. Sistema brasileiro de classificação de solo. Rio de Janeiro: Embrapa Solos, 2006. 306 p.

FERNÁNDEZ-QUINTANILLA, C.; SAAVEDRA, M. S.; GARCIA TORRES, L. Ecologia de las malas hierbas. In: GARCIA TORRES, L.; FERNÁNDEZ-QUINTANILLA, C. Fundamentos sobre malas hierbas y herbicidas. Madrid: Mundi-Prensa, 1991. p. 49-69.

KISMANN, K. G.; GROTH, D. Plantas infestantes e nocivas. 2.ed. São Paulo: BASF, 1999. Tomo II. 978 p.

KLEIN, A.; FELIPPE, G. M. Efeito da luz na germinação de sementes de ervas invasoras. Pesq. Agropec. Bras., v. 26, n. 7, p. 955-966, 1991.

LORENZI, H. Plantas daninhas do Brasil: terrestres, aquáticas, parasitas, tóxicas e medicinais. 3.ed. Nova Odessa: Instituto Plantarum, 2000. 608 p.

MACHADO NETO, J.G.; PITELLI, R.A. Profundidade de semeadura na emergência de amendoim-bravo. Pesq. Agropec. Bras., v. 23, n. 11, p. 1203-1208, 1988
MAGUIRE, J. D. Speed of germination aid selection and evaluation for seedling emergence and vigor. Crop Sci., v. 2, n. 2 , p. 176-177, 1962.

MURDOCH, A. J.; CARMONA, R. The implications of the annual dormancy cycle of buried weed seeds for novel methods of weed control. In: BRIGHTON CROP PROTECTION CONFERENCE - WEEDS, 1993, Brighton Proceedings... Brighton: British Crop Protection Association, 1993.p. 329-334.

MUNIZ FILHO, A. et al. Capacidade de emergência de picãopreto em diferentes profundidades de semeadura. R. Biol. Ci. Terra, v. 4, n. 1, 2004.

RADOSEVICH, S. R.; HOLT, J. S. \& GHERSA, C. M. Ecology of weeds and invasive plants: Relationship to agriculture and natural resource management. 3.ed. Hoboken John Wiley \& Sons, 2007.

ROBERTS, H. A. Seed banks in the soil. Adv. Appl. Biol., v. 6, p. $1-55,1981$.

SAHOO, U. K.; JHA, L. K. Effect of depth and duration of burial on seed viability and dormancy of Bidens pilosa $\mathrm{L}$. and Richardsonia pilosa H. B. K. Seed Res., v. 25, n. 1, p. 5-10, 1998.

TEMPLETON, A. R.; LEVIN, D. A. Evolutionary consequences of seed pools. Am. Natur., v. 114, p. 232- 249, 1979.

TOLLEDO, R. E. B.; KUVA, M. A.; ALVES, P. L. C. A. Fatores que afetam a germinação emergência de Xanthium strumarium L.: dormência, qualidade da luz e profundidade de semeadura. Planta Daninha, v. 11, n.1/2, p. 15-20, 1993.

VOLL, E. et al. Embebição e germinação de sementes de capim-marmelada. R. Bras. Sementes, v. 19, n. 1, p. 58-61, 1997. 